\title{
SUSCEPTIBILITY OF A SMART HOME TO INTENTIONAL ELECTROMAGNETIC INTERFERENCE ATTACKS
}

\author{
Sukhrob Davlyatov ${ }^{1 *}$, Tarek Mahfouz ${ }^{2}$, James W. Jones ${ }^{3}$, Sherif Attallah ${ }^{4}$ \\ *1,2,3,4 Department of Technology, Ball State University, USA \\ EmailID: *1sdavlyatov@bsu.edu; ${ }^{2}$ tmahfouz@bsu.edu; ${ }^{3}$ wjones@bsu.edu; ${ }^{4}$ soattallah@bsu.edu
}

Corresponding Author: -

Email: sdavlyatov@bsu.edu

\begin{abstract}
: -
Technology advancements are shaping the construction industry gradually. Smart homes have become a reality and in some cases a trend due to these advancements. Although the literature includes multitude of efforts addressing the technologies used in smart homes, integration processes, and privacy issues, little exists about their vulnerability to Intentional ElectroMagnetic Interference (IEMI). In an attempt to address this gap, the purpose of this paper is to investigate the proliferation of smart home technologies, their susceptibility to IEMI attacks, currently available mechanisms of defense, and to provide a cost assessment model of the most suited protection approaches to be adopted by the construction industry. To that end, the adopted research methodology collected and analyzed a set of relevant peer reviewed publication within the domain, and developed different construction cost estimates utilizing standard reference books, like RSMeans, and direct contact with system suppliers. The outcomes of the aforementioned methodology yielded two potential protection methods, namely full protection of the home shell; and partial protection for essential components while providing a detection system of potential attacks. The average achieved costs per square foot range from $\$ 7.91$ to $\$ 20.11$ depending on the selection of material and type of finish. It is instigated that the outcomes of this research provide a much-needed knowledge about the propensity of smart homes to IMEI attacks and provide a guidance cost estimate for protection mechanism. It also provides a better understanding for home owners regarding their decisions.
\end{abstract}

Keywords: -Smart Homes, ElectroMagnetic Interference, Intentional ElectroMagnetic Interference, Cost Assessment

\section{(c) $(\$)$}




\section{INTRODUCTION}

Nowadays, technology advancements have major impact on humans' lives. New advancements in medicine, treatment, and information among others have become possible due to quick developments in technology. Similarly, the construction industry has been affected by such advancements. New construction materials, methods, and methodologies have been introduced. Inevitably, the residential sector has also seen its share ranging from the concepts of modularization to automation processes. With the increase in the market of so called "Internet of Things", the idea of retrofitting an already existing or building a new Smart Home is becoming more realistic. According to reference [1], a typical family home will have more than 500 connected devices by 2022. Furthermore, major corporations like AT\&T, Verizon, and Google are positioning themselves for the market change by acquiring existing firms who specialize in smart home technologies and by developing their own platforms.

The idea of enhancing the comfort, security, and convenience level of occupants through advancements of computing and information technologies within homes [2] has gained more momentum over the last decade. Recently, the State of California has initiated the "Smart Housing Initiative", through the California Emerging Technology Fund, which requires broadband connectivity as part of the construction specifications in low-income housing build through public funding [3]. A similar initiative under the title of "Smart Infrastructure Initiative" was also adopted by California to equip infrastructure projects, including transportation, water, education, and other community facilities projects, with broadband capability within the construction stage. Within these strategies "(a) all public buildings are constructed with state-of-theart broadband connectivity and are available as stationery locations for wireless networks; and (b) rights-of-way associated with the construction of other infrastructure are available for broadband conduit or wireless towers." [3]. Similarly, the State of Texas has initiated the "S.M.A.R.T. Housing Policy" within the city of Austin [4]. The aforementioned examples highlight the current trend expansion in adopting Smart Housing within the construction industry.

Academic researchers and multitude of commercial companies have addressed this issue, within the residential and infrastructure sectors, in regards to its concept ([5] and [6]), technologies ([2] and [7]), breach of customers' privacy ([8] and [9]). However, little there is in the literature that addresses the vulnerability of Smart Homes against Intentional ElectroMagnetic Interference (IEMI).

Thus, the purpose of this paper is to consider the growing area of smart home technologies in the context of potential IEMI. This is achieved through literature review of previously published materials to provide a comprehensive overview of IEMI phenomena and explain how such an attack may impact electronic devices inside a smart home. The paper also investigates the most common defense mechanisms and identifies the most appropriate ones that could be appropriately applied in a home that employs smart technologies. Finally, a model cost assessment of the proposed IEMI defense mechanisms is provided.

The following parts of this paper is devoted to the discussion of

- Research Methodology:

- This section details the different stages of the research methodology.

- Proliferation of Smart Home Technologies:

- This section introduces the reader to the history and concepts of smart homes as well as its technologies.

- History of IEMI and Its Potential Impact on Smart Home:

- This section provides essential knowledge about IEMI and smart homes vulnerability parameters to such attacks.

- IEMI Defense Mechanisms:

- This section provides the reader with knowledge about the available defense mechanism against IMEI within the residential, commercial, and industrial sectors.

- Cost Assessment Model:

- This section provides a construction direct cost evaluation of the best identified defense mechanism.

- Conclusion

\section{Research Methodology}

The research methodology implemented to achieve the aforementioned research objective is fourfold as indicated in Fig. 1. First, a comprehensive search of peer-reviewed publication, including journals and conference proceedings, as well as magazines was undertaken to define the current state of knowledge in relation to smart housing technologies and construction. To that end, search engines including, but not limited to the American Society of Civil Engineers (ASCE), Canadian Society of Civil Engineers (CSCE), Google Scholar, IEEE, NASA Reference Publications, and Business Insider were utilized. The search yielded a total of 61 publications. Second, the content of each of these publications was examined to determine its relevance to the current research task for inclusion and exclusion purposes. Third, the final set of publications, a total of 23, were categorized into 3 categories, namely Proliferation of Smart Home Technologies, History of IEMI and Its Impact on Smart Home, and IEMI Defense Mechanisms. Fig. 2 illustrates the breakdown of the final collected documents per the identified research category. Finally, a cost assessment model for the best defense mechanism was developed.

\section{III.Proliferation of Smart Home Technologies}

The idea of smart homes is not a novelty, it goes as far back as 1980s. At that time, Xerox worked on a project titled "Ubiquitous Computing". According to reference [5], ubiquitous computing "created a new field in computer science, one that speculated on a physical world richly and invisibly interwoven with sensors, actuators, displays, and computational elements, embedded seamlessly in the everyday objects of our lives and connected through a continuous 
network". Today this idea of "ubiquitous computing" is manifested in smart home technologies and is defined as a "residence equipped with computing and information technology which anticipates and responds to the needs of the occupants, working to promote their comfort, convenience, security and entertainment through the management of technology within the home and connections to the world beyond" [2]. Consequently, a smart home is a system of interconnected devices that range from security sensors to home appliances, like dishwasher or a TV, that are capable to be operated remotely (e.g. via a mobile phone), and that are able to analyze residents' behavior and make decisions as to the efficiency (e.g. energy consumption management), and security (auto 911 dial in case of emergency).

The primary perceived apprehensions for proliferation of smart home technologies are the cost of technology and concern for breach of customers' privacy [8]. However, 75\% of Americans already have wireless internet at home and $89 \%$ of millennials own 3 or more devices that are connected to internet [9]. This is the sign that the trend is real and the current society is moving toward increased integration of technology in a typical residential home. Most major corporations are already in the game and the competition is intense in the smart home market. Smart home technologies market is already penetrated by such products as Xfinity Home, AT\&T Digital Home, ADT Pulse, TWC Intelligent Home, Nest, Lowe's Iris, Phillips Hue and Staples Connect [9]. These companies offer a wide variety of home automation solutions such as intelligent thermostat, home monitoring cameras, master remote control, automatic outdoor/indoor lighting, doors that can be locked/unlocked from a remote location among other services.

With such trends, the paradox is that the primary reason customers desire to adopt smart home technologies is security [8], while the primary reason customers are hesitant to adopt the technology is lack of said security. Most consumers are concerned that their network that connects devices in a smart home could be hacked. In addition to these vulnerabilities, a major potential weakness that is rarely discussed within the domain of smart homes is IMEI. Although it is less commonly known, it represents one of the most potentially dangerous vulnerability of smart home devices.

\section{Methodology Stages}

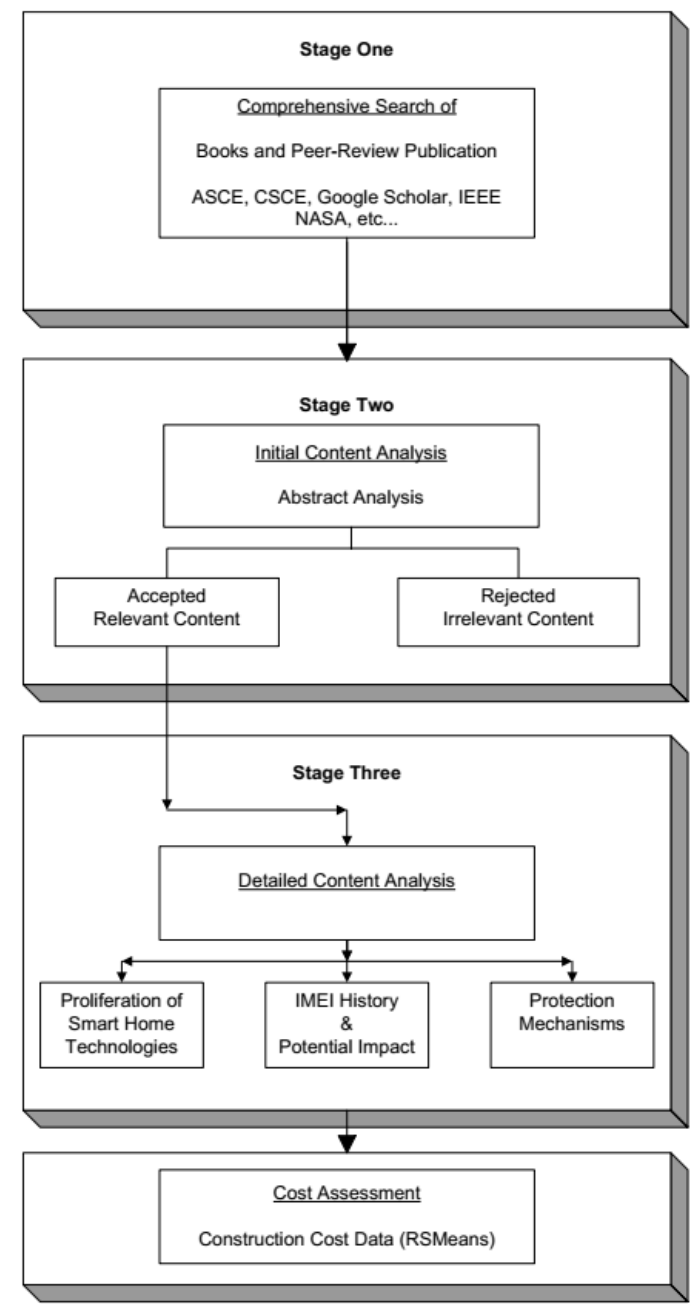

Fig. 1 Research Methodology 


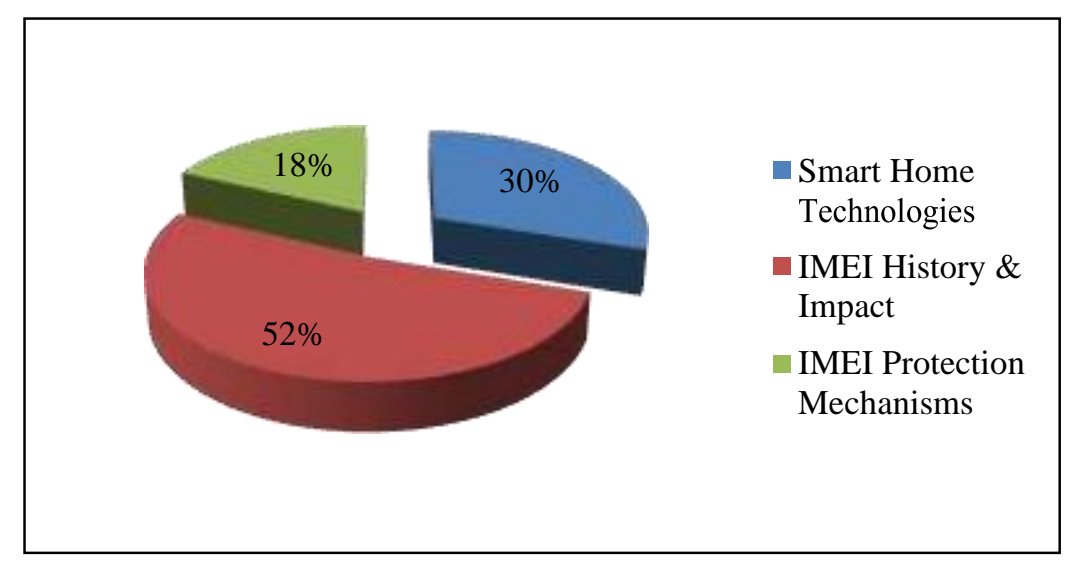

Fig. 2 Percentage Distribution of Collected Documents

\section{IV.History of IMEI and Its Potential Impact on Smart Homes}

Electromagnetic interference comes in several varieties. It can be caused by events of nature, such as lightning or electrostatic discharge [10]. It can also be a by-product of various working electronic devices. It could be caused unintentionally due to the lack of knowledge of technical specifications of electronic devices on hand, or it can be intentional where an individual has some malicious goal in mind. On a larger scale, it can be caused by a high-altitude nuclear explosion (HEMP). Generally, Intentional ElectroMagnetic Interference (IEMI) is defined as "Intentional malicious generation of electromagnetic energy introducing noise or signals into electric and electronic systems, thus disrupting, confusing or damaging these systems for terrorist or criminal purposes" [11]. For the purposes of this paper, the focus is targeted towards on non-explosive variants of IEMI.

There are two approaches for an IEMI attack to be launched, namely wireless and hardwired. A wireless IEMI is more flexible, however with the distance, signal strength may fade quickly. With hardwired IEMI, attack will be stronger, but more access to the home is needed. IEMI can either produce a disruption which may require manual restart, corrupt data, or even permanently damage electronic equipment [12], [13], [14], and [15]. It can be easily perceived that any of these outcomes could pose a serious risk to the devices inside a smart home.

Furthermore, IEMI is classified into a narrowband or a wideband (sometimes called ultra-wideband). Narrowband IEMI occupies a single frequency, while wideband IEMI, on the other hand, occupies a range of frequencies [11]. The former is more likely to lead to permanent damage of an electronic device because all the energy generated is channeled to a specific frequency [11]. However, its limiting factor is that each device in a smart home might have a different frequency at which its vulnerability can be exploited. With wideband IEMI, on the other hand, the generated energy is transmitted across multiple frequencies at the same time. This allows disrupting multiple devices simultaneously. However, the power and energy rating at each frequency is lower compared to a narrowband IEMI and, therefore, the probability of permanent damage is lower [11]. For the purposes of this paper, all types of electromagnetic interferences are generalized under the title of IEMI.

Traditionally, the area of IEMI is traditionally a military and academic subject. It used to be that devices that could generate an IEMI were extremely sophisticated in nature and required an advanced knowledge of physics and engineering as well as vast resources to manufacture and put in use. Most importantly, they required a lot of power to generate an attack to make an impact. However, in today's world, the IEMI susceptibility of smart home devices is increased due to the following reasons: (1) These devices operate at low voltages and less energy is needed to cause an upset in the system; (2) Density in today's electronic devices is increased substantially; and (3) Entire systems are placed on a single chip and the IEMI can cause an upset in the entire system as opposed to a standalone element [16]. As a result, anyone with a basic understanding of engineering and an access to Internet can build a device that does not require much power, is relatively small in size, and is very effective in generating an IEMI. Mr. David Schriner, in a testimony before the 1999 Joint Economic Committee Hearing, stated that an IEMI device, the size of a small briefcase, could be built in about a week and at a cost of $\$ 300$. All it takes is a car ignition parts and a camera battery for a power supply, TV dish antenna for focusing and aiming, and a handful of other parts that could be picked up at a nearby electronics junk store [17]. Studies show that in an unprotected environment system disruption or event permanent damage could be caused from a distance as far as 500 meters even if an electronic device is not powered on [10].

Furthermore, the impact of an IMEI attack can cause damage beyond the present electronic devices within a vicinity of a home. It could have a devastating impact on infrastructure of a smart home. Historically, in 1995 NASA published a report authored by Leach R.D., and Alexander, M.D., summarizing some of the documented instances of system failures attributed to electromagnetic interference. Mercedes-Benz's early ABS systems exhibited severe brake problems along a certain road in Germany. It was eventually discovered that a nearby radio transmitter was emitting strong enough electromagnetic fields causing the issues in the ABS system. In another unfortunate case, a heart attack victim who was transported to a local hospital died because of the medical equipment malfunction. It was discovered that the ambulance didn't have the proper shielding and strong radio signal resulted in unintentional electromagnetic interference in medical equipment.

While the focus of this paper is not on IEMI caused by explosions, it is educative to point out some of the ramifications of such recorded and documented attacks. In 1962 the U.S. tested Starfish, a nuclear bomb that was exploded at $400 \mathrm{~km}$ (over 248 miles) altitude. The electromagnetic fields generated by the explosion caused malfunctions and even 
failures to various systems including street lights and telecom systems as far as $1,400 \mathrm{~km}$ (870 miles) faraway. In that same year, USSR tested several nuclear bombs in Kazakhstan. The electromagnetic fields generated by high-altitude explosions fused over $570 \mathrm{~km}$ (354 miles) of telephone lines, overloaded a 1000km (621 miles) communications cable and damaged power line insulators [18]. These documented stories indicate that a well-planned IEMI attack could pose a significant threat to the infrastructure of a smart home.

As mentioned earlier, IEMI can cause a disruption or even a permanent damage to electronic devices inside a smart home. This creates several risks to the proper functioning of a Smart Home, including the following: loss of money, sensitive data loss, substantial inconvenience, health hazards (in the case of those with electronic medical devices). Since the concern is a fact, it is essential to determine the precautionary efforts taken by vendors of devices operated inside a Smart Home to minimize these risks. Based on literature review of scholarly publications and marketing materials posted on respective web-sites of selected vendors, it was identified that while most vendors strive to make their technologies secure against the risk of IEMI attack, these efforts are not specifically published.

\section{IMEI Defense Mechanisms}

As mentioned earlier, the area of IEMI has been widely studied by military and academia. The International Electrotechnical Commission (IEC) has been developing reports and standards related to electromagnetic interferences. Specifically, IEC's SC 77C commission is tasked to develop standards to protect civilian equipment and systems from IEMI threats [19]. In addition, Dr. William Radasky extensively studied IEMI threats and ways to reduce the risk of its impact [12]. For instance, to reduce the risk of wired attacks, it is recommended to pass all the cables entering a home through a specially designed surge arrested and a filter protection device attached to a low-inductance grounding system which will provide a level of protection against an IEMI [20]. In regards to wireless attacks, the most efficient way to reduce the impact of an IEMI is to put as much distance between a perpetrator and a Smart Home because the signal strength from the IEMI generator will attenuate greatly with traveled distance. Hence, in some areas, putting a fence around the Smart Home would be the most efficient way to reduce the impact of an IEMI. However, this method might not be feasible in urban areas.

Furthermore, the literature in this domain an effective means of curbing the impact of an IEMI attack through reinforcing the skeleton of a smart home with metal. However, one must be cautious, as many smart home technologies utilize electromagnetic radio waves to transmit information, metal reinforcement can significantly reduce the operational range of such devices. As such, one method is to use metal reinforcement on outer walls of the Smart Home. Another way, perhaps, is to consolidate all the critical devices in one metal reinforced room.

However, windows pose critical vulnerability to IEMI as glass is transparent to electromagnetic fields. Ideally, no windows would solve the issue. However, one cannot imagine a Smart Home without large windows. Therefore, the possible solution is to use metal mesh screens to cover the windows which will help reduce the impact of an IEMI attack. On the other hand, the transparency of glass can be used in the favor of Smart Home protection. For instance, the network cabling could be replaced with optic fiber connections, which use light to transmit information and not the electric current. Hence, optic fiber is transparent to IEMI attacks.

Perhaps, the most advantageous way to deal with IEMI attacks is to install a sensory device that would detect the IEMI attack at early stages and shutdown sensitive electronics before the attack can make any permanent damage. Some prototypes in this area have been built and tested [21]. Some products are available for purchase. For instance, Emprimus, a Minneapolis based company, offers an IEMI detector that can provide a real-time identification of an IEMI attack [22].I

\section{Cost Assessment Model}

The aforementioned discussion provides an understanding of the potential impact of IMEI, and provides number of safety guards to protect smart homes. However, these alternatives might cause an additional financial burden to owner. As a result, a cost assessment of associated financial parameters with any of these alternatives is much needed. To that end, the analysis of each proposed alternative is made while trying to provide full protection for a smart home. As a result, the proposed alternatives include

(1) full protection of the home shell; and (2) partial protection for essential components while providing a detection system of potential attacks. Cost data needed for the addressing each of the alternatives is attained from RSMeans Construction Data and direct contact with system suppliers. All estimates are provided per square foot of wall or roof as illustrated in the following sections.

\section{A. Shell Protection}

To provide a full protection of the shell of a smart home against IEMI, two alternatives are assessed, namely (1) exterior wall and roof finish, and (2) interior wall and roof finish.

1) Exterior Wall and Roof Finish: To provide full protection against IEMI and to offer options of customization for owners, different metal siding for walls and roofs are investigated. To that end, corrugated and flat steel panels with insulation are assessed for walls and roofs. However, as mentioned earlier, glass windows provide a weakness against IEMI. To address this point, steel reinforced glass for windows is adopted to present a full protection for a smart home. Table I provides the extracted information from RSMeans. The cost data represent bare cost. As a result, labor burdens, sales tax, and location adjustments need to be assigned to achieve a representative cost per square foot of the addressed items. To that end, Muncie, Indiana is chosen as the designated location for performing the works. Total adjusted cost values are provided in Table II. The calculated values highlight the following exterior costs per square foot based on the 
combination of selected materials indicated in Table III.

- Cost per square foot of wall area, depending on the finish adopted, ranges from $\$ 4.81$ to $\$ 11.61$.

- Cost per square foot of roof area, depending on the finish adopted, ranges from \$5.12 to \$8.57.

- Cost per square foot of glass for windows is estimated at \$24.93.

Table I. Exterior Bare Cost Data (RS Means Construction Cost Data)

\begin{tabular}{|c|c|c|c|c|c|c|}
\hline Item Code & Item Description & Crew & Productivity & Units & Material Cost & Labor Cost \\
\hline 0721 & Foam Insulation & & & & & \\
\hline 072113.13 & Foam Board Insulation & & & & & \\
\hline 072113.130700 & $2 "$ thick, RB & 1 Carp & 675 & S.F. & $\$ 0.62$ & $\$ 0.47$ \\
\hline 072116.20 & Blanket Insulation for Walls & & & & & \\
\hline 072116.200020 & $\begin{array}{l}\text { Craft Forced Fiberglass, 3-1 1/2" } \\
\text { thick, R11, 15" wide }\end{array}$ & 1 Carp & 1350 & S.F. & $\$ 0.34$ & $\$ 0.24$ \\
\hline 072216.10 & Roof Deck Insulation & & & & & \\
\hline 072216.100700 & $\begin{array}{l}\text { Fiberglass 2-7/16" thick, high } \\
\text { density, R10 }\end{array}$ & 1 Rafc & 800 & S.F. & $\$ 1.55$ & $\$ 0.34$ \\
\hline 072216.101530 & 3" thick, Foam glass, R9 & 1 Rafc & 700 & S.F. & $\$ 2.75$ & $\$ 0.39$ \\
\hline 0741 & Roof Panels & & & & & \\
\hline 074113.20 & Steel Roofing Panels & & & & & \\
\hline 074113.200400 & $\begin{array}{l}24 \text { Gauge, corrugated or ribbed, } \\
\text { galvanized finish }\end{array}$ & G-3 & 950 & S.F. & $\$ 2.91$ & $\$ 1.33$ \\
\hline 074113.200600 & $\begin{array}{l}\text { Colored, } 24 \text { Gauge, corrugated } \\
\text { or ribbed, galvanized finish }\end{array}$ & G-3 & 1050 & S.F. & $\$ 1.68$ & $\$ 1.2$ \\
\hline 074113.200715 & $\begin{array}{l}\text { Flat Profile, } 24 \text { gauge, 1-3/4" } \\
\text { standing seams, 10" } \\
\text { galvanized }\end{array}$ & G-3 & 950 & S.F. & $\$ 4.51$ & $\$ 1.33$ \\
\hline 074113.200730 & $\begin{array}{l}\text { Flat Profile, } 24 \text { gauge, 1-3/4" } \\
\text { standing seams, } 10^{\prime \prime} \text { wide, zinc } \\
\text { aluminum alloy finish }\end{array}$ & G-3 & 950 & S.F. & $\$ 3.64$ & $\$ 1.33$ \\
\hline Item Code & Item Description & Crew & Productivity & Units & Material Cost & Labor Cost \\
\hline 0742 & Wall Panels & & & & & \\
\hline 074213.30 & Steel Siding & & & & & \\
\hline 074213.300400 & $\begin{array}{l}24 \text { Gauge, corrugated or ribbed, } \\
\text { galvanized finish }\end{array}$ & G-3 & 785 & S.F. & $\$ 1.79$ & $\$ 1.62$ \\
\hline 074213.301000 & $\begin{array}{l}\text { Colored, } 24 \text { Gauge, corrugated } \\
\text { or ribbed, galvanized finish }\end{array}$ & G-3 & 790 & S.F. & $\$ 2.29$ & $\$ 1.6$ \\
\hline 074213.301200 & $\begin{array}{l}\text { Factory Sandwich Panels, I" } \\
\text { insulation, } 26 \text { gauge }\end{array}$ & & & & & \\
\hline 074213.301300 & Colored 1 Side & G-3 & 380 & S.F. & $\$ 5.9$ & $\$ 3.32$ \\
\hline 074213.301500 & Galvanized 2 Sides & G-3 & 380 & S.F. & $\$ 7.3$ & $\$ 3.32$ \\
\hline 074213.301600 & Colored 2 Sides & G-3 & 380 & S.F. & $\$ 7.6$ & $\$ 3.32$ \\
\hline 0881 & Glass Glazing & & & & & \\
\hline 088165 & Wire Glass & & & & & \\
\hline 088165.10 & Glass Reinforced with wire & & & & & \\
\hline 088165.101000 & $\begin{array}{l}\text { Polished wire, } 1 / 4^{\prime \prime} \text { thick, } \\
\text { diamond clear }\end{array}$ & 2 Glaz & 135 & S.F. & $\$ 18.75$ & $\$ 4.57$ \\
\hline
\end{tabular}


Table II. Adjusted Exterior Cost Data for Muncie Indiana (RSMeans Construction Cost Data)

\begin{tabular}{|c|c|c|}
\hline Item Code & Item Description & Total Unit Cost \\
\hline 0721 & Foam Insulation & \\
\hline 072113.13 & Foam Board Insulation & \\
\hline 072113.130700 & 2" thick, RB & $\$ 1.18$ \\
\hline 072116.20 & Blanket Insulation for Walls & \\
\hline 072116.200020 & Craft Forced Fiberglass, 3-1 1/2" thick, R11, 15" wide & $\$ 0.63$ \\
\hline 072216.10 & Roof Deck Insulation & \\
\hline 072216.100700 & Fiberglass 2-7/16" thick, high density, R10 & $\$ 2.02$ \\
\hline 072216.101530 & 3" thick, Foam glass, R9 & $\$ 3.31$ \\
\hline 0741 & Roof Panels & \\
\hline 074113.20 & Steel Roofing Panels & \\
\hline 074113.200400 & 24 Gauge, corrugated or ribbed, galvanized finish & $\$ 4.51$ \\
\hline 074113.200600 & Colored, 24 Gauge, corrugated or ribbed, galvanized finish & $\$ 3.1$ \\
\hline 074113.200715 & Flat Profile, 24 gauge, 1-3/4" standing seams, 10 " wide, galvanized & $\$ 6.15$ \\
\hline 074113.200730 & Flat Profile, 24 gauge, 1-3/4" standing seams, 10" wide, zinc aluminum alloy finish & $\$ 5.26$ \\
\hline 0742 & Wall Panels & \\
\hline 074213.30 & Steel Siding & \\
\hline 074213.300400 & 24 Gauge, corrugated or ribbed, galvanized finish & $\$ 3.69$ \\
\hline Item Code & Item Description & Total Unit Cost \\
\hline 074213.301000 & Colored, 24 Gauge, corrugated or ribbed, galvanized finish & $\$ 4.18$ \\
\hline 074213.301200 & Factory Sandwich Panels, 1" insulation, 26 gauge & \\
\hline 074213.301300 & Colored 1 Side & $\$ 9.86$ \\
\hline 074213.301500 & Galvanized 2 Sides & $\$ 11.3$ \\
\hline 074213.301600 & Colored 2 Sides & $\$ 11.61$ \\
\hline 0881 & Glass Glazing & \\
\hline 088165 & Wire Glass & \\
\hline 088165.10 & Glass Reinforced with wire & \\
\hline 088165.101000 & Polished wire, $1 / 4$ " thick, diamond clear & $\$ 24.93$ \\
\hline
\end{tabular}

Table III. Cost per Square Foot of Exterior Items Based on Material Selection

\begin{tabular}{|c|c|}
\hline Item Description & $\operatorname{Cost} / \mathrm{ft}^{2}$ \\
\hline \multicolumn{2}{|l|}{ Wall Panels } \\
\hline Colored, 24 Gauge, corrugated or ribbed, galvanized finish with Blanket Insulation for Walls & $\$ 4.81$ \\
\hline Colored, 24 Gauge, corrugated or ribbed, galvanized finish with Foam Board Insulation & $\$ 5.36$ \\
\hline Factory Sandwich Panels, 1" insulation, 26 gauge, Colored 1 Side & $\$ 9.86$ \\
\hline Factory Sandwich Panels, 1" insulation, 26 gauge, Colored 2 Side & $\$ 11.61$ \\
\hline \multicolumn{2}{|l|}{ Roof Panels } \\
\hline Colored, 24 Gauge, corrugated or ribbed, galvanized finish with Fiberglass 2-7/16" thick, high density, R10 & $\$ 5.12$ \\
\hline Colored, 24 Gauge, corrugated or ribbed, galvanized finish with 3" thick, Foam glass, R9 & $\$ 6.41$ \\
\hline $\begin{array}{l}\text { Flat Profile, } 24 \text { gauge, 1-3/4" standing seams, 10" wide, galvanized, with Fiberglass 2-7/16" thick, high density, } \\
\text { R10 }\end{array}$ & $\$ 8.17$ \\
\hline Flat Profile, 24 gauge, 1-3/4" standing seams, 10" wide, galvanized, with 3" thick, Foam glass, R9 & $\$ 9.46$ \\
\hline $\begin{array}{l}\text { Flat Profile, } 24 \text { gauge, 1-3/4" standing seams, } 10 \text { " wide, zinc aluminum alloy finish, with Fiberglass } 2-7 / 16 " \text { thick, } \\
\text { high density, R10 }\end{array}$ & $\$ 7.28$ \\
\hline Flat Profile, 24 gauge, 1-3/4" standing seams, 10" wide, zinc aluminum alloy finish, with 3" thick, Foam glass, R9 & $\$ 8.57$ \\
\hline \multicolumn{2}{|l|}{ Glass Glazing } \\
\hline Polished wire, 1/4" thick, diamond clear & $\$ 24.93$ \\
\hline
\end{tabular}

2) Interior Wall Finish: In an attempt to maintain the exterior aesthetics of a smart home and to provide owners with the possibility of customizing exteriors, changing the traditional interior gypsum board to metal sheets provides the aforementioned goal and the needed protection against IMEI. To that end, structural steel plates with paints and protection coating is proposed. Table IV provides the extracted information from RSMeans. Similarly, to achieve a representative cost estimate, Muncie Indiana is designated as the location for performing the works. Table V highlights the adjusted unit costs for the aforementioned location.

The calculated values highlight the following interior costs per square foot based on the combination of selected materials indicated in Table VI.

- Cost per square foot of wall area, depending on the finish adopted, ranges from $\$ 8.35$ to $\$ 31.80$. 
Table IV. Interior Bare Cost Data (RSMeans Construction Cost Data)

\begin{tabular}{|c|c|c|c|c|c|c|}
\hline Item Code & Item Description & Crew & Productivity & Units & Material Unit Cost & Labor Unit Cost \\
\hline 0512 & Structural Steel Framing & & & & & \\
\hline 051223 & Structural Steel for Building & & & & & \\
\hline 051223.65 & Plates & & & & & \\
\hline $\begin{array}{l}051223.65 \\
0050\end{array}$ & 1/8" thick (5.1 lb./S.F.) & & & S.F. & $\$ 7.65$ & \\
\hline $\begin{array}{l}051223.65 \\
0100\end{array}$ & $1 / 4$ " thick $(10.2 \mathrm{lb} . / \mathrm{S} . \mathrm{F})$. & & & S.F. & $\$ 15.30$ & \\
\hline $\begin{array}{l}051223.65 \\
0300\end{array}$ & 3/8" thick (15.3 lb./S.F.) & & & S.F. & $\$ 23.00$ & \\
\hline $\begin{array}{l}051223.65 \\
0400\end{array}$ & 1/2" thick (20.4 lb./S.F.) & & & S.F. & $\$ 30.50$ & \\
\hline 6510 & Structural Steel Treatment & & & & & \\
\hline 6520 & alkyds Primer & 2Psst & 3600 & S.F. & $\$ 0.06$ & $\$ 0.12$ \\
\hline 6540 & Gloss Top Coat & 2Psst & 3200 & S.F. & $\$ 0.05$ & $\$ 0.14$ \\
\hline
\end{tabular}

Table V. Adjusted Exterior Cost Data for Muncie Indiana (RSMeans Construction Cost Data)

\begin{tabular}{|c|c|c|c|c|}
\hline Item Code & & Item Description & Units & Total Unit Cost \\
\hline 0512 & & Structural Steel Framing & & \\
\hline 051223 & & Structural Steel for Building & & \\
\hline 051223.65 & & Plates & & \\
\hline 051223.650050 & & 1/8" thick (5.1 lb./S.F.) & S.F. & $\$ 7.85$ \\
\hline 051223.650100 & & $1 / 4^{\prime \prime}$ thick (10.2 lb./S.F.) & S.F. & $\$ 15.70$ \\
\hline 051223.650300 & & 3/8" thick (15.3 lb./S.F.) & S.F. & $\$ 23.60$ \\
\hline \multirow[t]{4}{*}{051223.650400} & & 1/2" thick (20.4 lb./S.F.) & S.F. & $\$ 31.30$ \\
\hline & 6510 & Structural Steel Treatment & & \\
\hline & 6520 & alkyds Primer & S.F. & $\$ 0.24$ \\
\hline & 6540 & Gloss Top Coat & S.F. & $\$ 0.26$ \\
\hline
\end{tabular}

Table VI. Cost per Square Foot of Interior Items Based on Material Selection

\begin{tabular}{lr}
\hline Item Description & Cost $\mathbf{f t}^{2}$ \\
\hline Structural Steel Plates & \\
1/8" thick (5.1 lb./S.F.) including paint \& protection coating & $\$ 8.35$ \\
$1 / 4 "$ thick (10.2 lb./S.F.) including paint \& protection coating & $\$ 16.20$ \\
3/8" thick (15.3 lb./S.F.) including paint \& protection coating & $\$ 24.10$ \\
\hline $1 / 2 "$ thick (20.4 lb./S.F.) including paint \& protection coating & $\$ 31.80$ \\
\hline
\end{tabular}

\section{B. Partial Protection}

The aforementioned two alternatives impose on home owners' constraints in regards to the choice of finish as well as the allowed level of customization. In attempt to resolve this paradigm, building a metal shielded room, which includes essential devices, while providing an IEMI detection system would present a plausible solution. To that end, any of the aforementioned options for exterior and/or interior protection methods could be adopted to shield the core room. However, to provide an approximated cost assessment of the detection system, the Emprimus system, mentioned previously, is adopted. For more information about the system refer to [22]. Although the system's use has been in commercial and industrial structures, it could be as adequately used in residential ones. For such purpose, "one EMP.Alert" ${ }^{\mathrm{TM}}$ placed either on the outside of the building or an interior wall is needed. In either case it is simply attached to the wall. The detector needs to be connected to the computer with fiber optic cable" [22]. However, the computer must be protected from IMEI within the shielded core room. To that end, an estimated lumpsum cost of the system is $\$ 15,000.00$ including the needed hardware, software, and installation. Since the optic fiber cable is not included within the abovementioned cost, RSMeans Construction Cost Data reference book is used to find the cost per linear foot. To that end, the total cost, including labor and material, ranges between $\$ 81.27$ to $\$ 68.9$ depending on the number of nodes needed.

\section{Conclusion}

This paper attempts on providing a review of smart home technologies and their susceptibility to IEMI attack. To that end, a comprehensive review of the literature within this domain was performed to identify (1) proliferations of smart home technologies; (2) IMEI history and impacts; and (3) available mechanisms of protecting homes against such attacks. In addition, RSMeans Construction Cost Data was utilized to develop cost assessment of the different identified mechanisms.

The research activity identified three potential mechanisms, namely External Shell metal shielding, internal shell metal shielding, and metal shielded room with a detection system. In regards to the first alternative, an average costs per square foot of supply and installation of walls, roof, and windows were estimated at $\$ 7.91, \$ 7.50$, and $\$ 24.93$ respectively. Whereas an average cost of $\$ 20.11$ per square foot was estimated for the second alternative. On the other hand, the cost of the third alternative is greatly dependent on the home design and area. 
The outcomes of this research provide a much-needed knowledge about the susceptibility of smart homes to IMEI attacks and provide a guidance cost estimate for protection mechanism. It instigated that it provides a better understanding for home owners regarding their decisions.

\section{VIII.Limitations and Future Works}

The current study provides costs per square foot of multiple building components including walls, roof, and windows. However, a major limitation is the nonexistence of an actual project to which these modifications could be implemented. This consideration and others will be the subject of future study by the authors, including the net cost per square foot due to material nature replacement as well as the cost of structural modifications needed if any.

\section{References}

[1].Jones, Nick, “The Future Smart Home: 500 Smart Objects Will Enable New Business Opportunities”, Gartner.com, 2014.

[2].Aldrich, K. F., "Smart Homes: Past, Present and Future”, R. Harper, Ed., Inside the Smart Home. London: Springer London, 2003, pp. 17-39.

[3].California Emerging Technology Fund (CETF). (2008) CETF page on Smart Housing Initiatives. [Online], Retrieved December 8, 2015. Available: http://www.cetfund.org/investments/initiative-smart-housing

[4].Neighborhood housing and community Development. (2008). Neighborhood housing and community Development page on S.M.A.R.T. Housing Policy. [Online]. Retrieved December 8, $2015 . \quad$ Available: https://www.austintexas.gov/sites/default/files/files/Housing/Application_Center/SMART_Housing/smart_guide_0708.pdf

[5].Weiser, M., Gold, R., \& Brown, J. S.. "The origins of ubiquitous computing research at PARC in the late 1980s," IBM Systems Journal, vol. 38 (4), pp. 693-695, 1999.

[6].Zhao, H. and Wu, D., "Definition, Function, and Framework Construction of a Smart Road," in Proc. International Symposium on Frontiers of Road and Airport Engineering, 2015, pp. 204-218.

[7].Ofei-Amoh, R. and Syal, M., "Installation Aspects of Smart Grid," Practice Periodical on Structural Design and Construction, vol. 18(1), pp. 56-66, 2013.

[8].iControl Networks. (2015). iControl Networks page on 2015 State of The Smart Home Report. [Online], Retrieved September 21, 2015. Available: iControl Insights Blog: http://www.icontrol.com/blog/2015-state-of-the-smart-homereport/

[9].Greenough, J. (2015). Business Insider page on The American Smart Home Market: 2015 [Slide Deck]. [Online], Retrieved September 21, 2015. Available: http://www.businessinsider.com/the-american-smart-home-market-2015slide-deck-2015-8

[10]. Backstrom, M., "The threat from intentional EMI against the civil technical infrastructure," in ESW2006, 3rd European Survivability Workshop, Toulouse, France, 2006.

[11]. Radasky, W., \& Savage, E., "Intentional Electromagnetic Interference (IEMI) and Its Impact on the U.S. Power Grid," Metatech Corporation, Goleta, CA, Meta-R-323, 2010.

[12]. Radasky, W. A. (2014). IEEE Spectrum page on Electromagnetic Warfare Is Here. [Online], Retrieved October 24, 2015. Available: http://spectrum.ieee.org/aerospace/military/electromagnetic-warfare-is-here/

[13]. Wilk, M. W., \& Radasky, A. W., "Intentional Electromagnetic Interference (IEMI)-Background and Status of the Standardization Work in the International Electrotechnical Commission (IEC)," in Proc. 27th URSI Gen. Assem., Maastricht, Olanda, 2002, p. 27.

[14]. Parfenov, V. Y., Zdoukov, L. N., Radasky, W. A., \& Ianoz, M., "Conducted IEMI Threats for Commercial Buildings," IEEE Transactions on Electromagnetic Compatibility, vol. 46 (3), pp. 404-411, 2004.

[15]. Kasmi, C., Lopes-Esteves, J., Picard, N., Renard, M., Beillard, B., Martinod, E., et al., "Event Logs Generated by an Operating System Running on a COTS Computer During IEMI Exposure," IEEE Transactions on Electromagnetic Compatibility, vol. 56 (3), pp. 1723-1726, 2014.

[16]. Leach, R. and Alexander, M.B., "Electronic System Failures and Anomalies Attributed to Electromagnetic Interference," NASA, MSFC, Alabama, NASA Reference Publication 1374, 1995.

[17]. Schriner, D., "Radio Frequency Weapons and Proliferation: Potential Impact on the Economy," J. E. Hearing, Interviewer, 1998.

[18]. Fachot, M. "iecetch page on TC work to help thwart potential threats: Preventing electromagnetic interference from nuclear and other weapons. [Online], Retrieved September 25, 2015. Available: http://iecetech.org/issue/201310/TC-work-to-help- thwart-potential-threats

[19].(2015) The International Electrotechnical Commission (IEC) website. [Online]. Available: http://www.iec.ch/dyn/www/f?p=103:7:0::::FSP_ORG_ID:1387

[20]. Brauer, F., Fahlbusch, S., ter Haseborg, J., \& Potthast, S., "Investigation of Hardening Measures for IT Equipment against Radiated and Conducted IEMI,“ IEEE Transactions on Electromagnetic Compatibility, vol. 54(5), pp. 1055, 2012.

[21]. Dawson, J. F., Flintoft, D. I., Marvin, A. C., \& Garbe, H., “A Cost-Efficient System for Detecting an Intentional Electromagnetic Interference (IEMI) Attack," in Proc. International Symposium on Electromagnetic Compatibility (EMC Europe 2014), Gothenburg, Sweden, 2014.

[22]. Emprimus. (2015). Emprimus page on Electromagnetic Threat Detection. [Online], Retrieved October $26,2015$. Available: Emprimus.com. 